KREATIF

Jurnal Ilmiah

Prodi Manaiemen Universitas Pamulang
Pamulang ISSN : 2339 - 0689, E-ISSN : 2406-8616

J. KREATIF, Vol. 7, No. 2, Desember 2019 (Halaman 73-83)

Tersedia Online di : http://openjournal.unpam.ac.id/index.php/kreatif

\title{
PENGARUH KEPEMIMPINAN TRANSFORMASIONAL DAN MOTIVASI KERJA TERHADAP KINERJA KARYAWAN PADA PT. TIRTA VARIA INTIPRATAMA DAAN MOGOT JAKARTA BARAT
}

\author{
Darmadi $^{1}$, Rahmad Setiawan ${ }^{2}$ \\ Program Studi Manjamen \\ ${ }^{1,2}$ Dosen Universitas Pamulang \\ dosen02445@unpam.ac.id
}

\begin{abstract}
ABSTRAK
Maksud penelitian ini mengetahui dampak kepemimpinan paruh waktu ,transformasional dan motivasi kerja untuk kinerja pegawaidi PT. Tirta Varia Intipratama Daan Mogot, Jakarta Barat.

Metode yang dipakai dalam penelitian menggunakan metode asosiatif. Penelitian ini semua penduduk adalah pekerja PT. Tirta Varia Intipratama Daan Mogot, Jakarta Barat. Sampel yang digunakan 120 res.pon.den. Teknik pengumpulan data angket dan teknik analisis data uji instrumentasi, uji asumsi klasik, regresi linier berganda, koefisien korelasi, koefisien determinasi, uji-t dan uji-F.

Hasilnya menunjukkan manajemen semi-transformatif memiliki dampak positif dan signifikan terhadap kinerja karyawan ketika jumlahnya adalah 4,019> $\mathrm{t}$ Tabel pada tahun 1984 dengan signifikan $0,000<0,05$. Motivasi kerja parsial memiliki dampak positif dan signifikan terhadap kinerja karyawan ketika ia dihitung 4.011> 1.984 dengan nilai signifikan $0,000<0,05$. Kepemimpinan transformatif dan motivasi kerja dampak positif dan signifikan terhadap kinerja karyawan dengan nilai Fcount 20,529> Ftable 3.07 dengan nilai 0,000 <0,05.

Kata Kunci : Kepemimpinan Transformasional, Motivasi Kerja dan Kinerja Karyawan
\end{abstract}

\section{ABSTRACT}

The purpose of this study was to determine the effect of part-time and transformational leadership and work motivation on employee performance at PT. Tirta Varia Intipratama Daan Mogot, West Jakarta.

The method used in this study uses an associative method. In this study, all residents are workers of PT. Tirta Varia Intipratama Daan Mogot, West Jakarta. The sample used in this study was 120 respondents. Data collection techniques using questionnaires and data analysis techniques using instrumentation test, classic assumption test, multiple linear regression, correlation coefficient, coefficient of determination, $t$-test and $F$-test.

The results showed that semi-transformative management had a positive and significant impact on employee performance when the number was 4,019> $t$ Table in 1984 with a significant 0,000 <0.05. Partial work motivation has a positive and significant impact on employee performance when it is calculated 4,011> 1,984 with a significant value of 0,000 <0.05. At the same time, 
transformative leadership and work motivation have a positive and significant effect on employee performance with a value of Fcount 20,529> Ftable 3.07 with a value of $0,000<0.05$..

Keywords: Transformational Leadership, Work Motivation and Employee Performance

\section{PENDAHULUAN}

\section{A. Latar Belakang Masalah}

Kinerja adalah kualitas atau kuantitas pekerjaan karyawan, berdasarkan standar kerja yang ditetapkan perusahaan.

Keberhasilan manajer kontrol melalui model manajemennya memberikan kepemimpinan dan kemampuan manajemen, bawahan, atasan, organisasi, dan lingkungan. Pengalaman sangat memengaruhi proses dan kinerja manajemen organisasi yang dikelola. "Transformasi Kepemimpinan dapat mengarahkan orang lain untuk melihat massa depan, semua yang ingin dicapai"

Mengenai penelitian empiris oleh Rahyuda. (2013), secara parsial variabel gaya kepemimpinan transformasional memberi dampak positif terhadap kinerja karyawan.

Faktor yang turut mempengaruhi kinerja karyawan yaitu motivasi kerja, Pada penelitian empiris yang dilakukan oleh Tambingon, Ghozali, Imam. 2013, Motivasi berpengaruh secara parsial pada pegawai.

B. Rumusan Masalah

Berdasarkan rumusan masalah dalam penelitian ini :

1. Seberapa besar pengaruh X1 memberi dampak positif dan meningkat terhadap kinerja karyawan PT. Tirta Varia Intipratama?

2. Seberapa besar X2 memberi dampak positif dan meningkat terhadap kinerja karyawan pada PT. Tirta Varia Intipratama?

3. Seberapa besar X1 dan X2 bersama-sama berpengaruh positif dan meningkat terhadap Y di PT. Tirta Varia Intipratama?

\section{LANDASAN TEORI}

\section{A. Kepemimpinan Transformasional}

Yukl (2013:313) mengngemukakan "Kepemimpinan Transformasi yaitu situasi dimana pengikut pemimpin yang mentransformasi merasakan kepercayaan, kekaguman, kesetiaan, dan rasa hormat terhadap pemimpin itu, dan termotivasi untuk melakukan lebih dari yang diharapkan, mendorong untuk menempatkan organisasi atau tim dalam peran yang lebih besar daripada diri mereka .

Avolio, B.J., Zhu, W., Koh, W., and Bhatia, P.( 2004) ada 4 indikator perilaku kepemimpinan transformasional:

1. Pengaruh yang ideal menekankan tipe pemimpin yang mengekspresikan pandangan, pandangan, dan mengagumi pengikut.

2. 2.Motivasi inspirasional menekankan bagaimana memotivasi dan menginspirasi bawahan dampak diharapkan dapat meningkatkan moral team

3. Stimulasi intelektual manajer yang mencoba membuat team kerja inovasi, kreativitas. 
4. 4.Pertimbangan yang dipersonalisasi menekankan manajer yang berfokus pencapaian kebutuhan team keja.

\section{B. Motivasi Kerja}

Sutrisno (2013:109) didefinisikan motivasi yaitu faktor faktor utama seseorang mengambil tindakan tertentu, motivasi sering diartikan sebagai faktor yang mendorong perilaku manusia. Ranupandojo, H., dan Suad Husnan (2002:146) mengelompokan motivasi menjadi 2 ialah:

1. Motivasi positif

Motivasi secara positif memengaruhi pegawai untuk bekerja sesuai kebutuhan manajemen dengan memberi penghargaan atau menghargai kinerja mereka

2. Motivasi negatif

Motivasi memiliki dampak negatif pada karyawan yang ingin melakukan pekerjaan, tetapi menggunakan sistem ancaman atau hukuman untuk memaksa karyawan melakukan sesuatu atau mengurangi upah mereka.

Adapun indikator motivasi kerja dipaparkan Priansa, Donni Juni (2014:205-212) antara lain:

1. Fisiologis

Apakah kebutuhan tingkat yang lebih rendah serta kebutuhan dasar para pemasok. Misalnya, kebutuhan untuk minum, minum, bernapas dengan benar.

2. Keamanan

Perlunya melindungi dari ancaman-ancaman, konflik, dan tempat tingal tidak hanya secara fisik, tetapi juga secara mental, psikologis, dan intelektual.

3. Kebutuhan sosial

Dia perlu diakuwi organisasi untuk bersatu, berfungsi, mencintai atau dicintai.

4. Kebutuhan untuk penilaian indvidu atau pengakuan (untuk penilaian)

Kebutuhan ini terkait kebutuhan saling menghormati ,menghargai orang lain di lingkungan tinggal.

5. Kebutuhan aktualisasi diri

Kebutuhan akan kekeahlian, skil kebutuhan akan pendapat, mengekspresikan gagasan, untuk memberikan sesuatu penghargaan.

\section{Kinerja Karyawan}

Definisi Sutrisno (2013: 151) menunjukkan bahwa pencapaian pekerjaan "yaitu hasil pencapeain karyawan raih melalui perilakunya dalam kinerja tugas kerja".

Definisi Bangun, Wilson (2012:233), kinerja dapat diukur, termasuk:

1. Volume kerjaan terdiri dari: volume kerjaan yang tuntaskan atau dicapai.

2. Kualitas pekerjaan, terdiri dari: kualitas kerja perlu disesuaikan agar dapat melakukannya dengan aturan.

3. Ketepatan waktu, terdiri dari: kerjaan yang ditangguhkan dan penyelesaian pekerjaan tepat waktu.

4. Kunjungan terdiri dari: tingkat kehadiran dan keterlambatan staf dalam organisasi. 
5. Keahlian kerja kolaboratif terdiri dari: Kemampuan untuk bekerja dengan baik antara pegawai dan menghormati.

\section{Kerangka Berfikir}

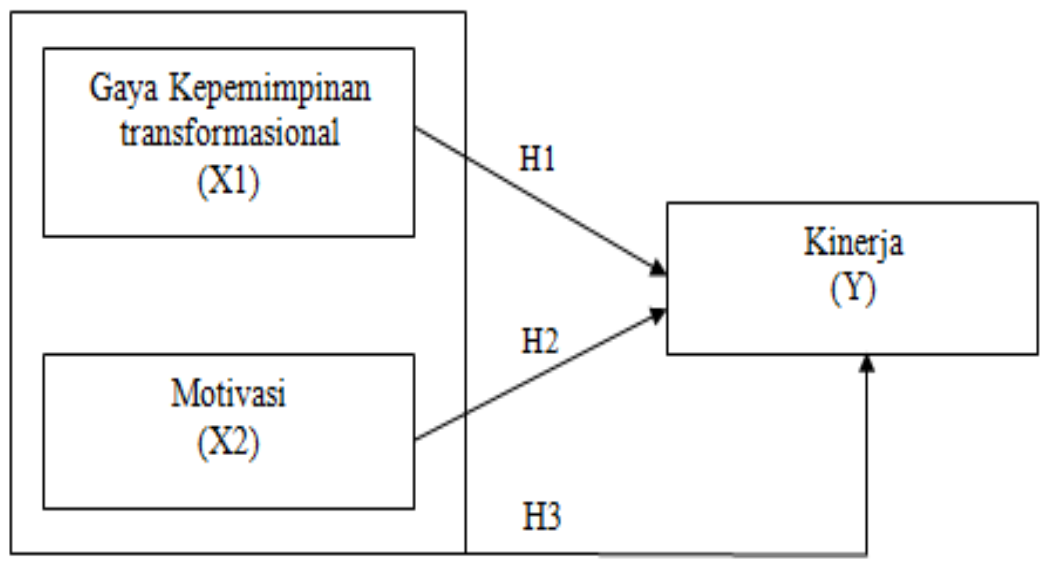

\section{E. Hipotesis}

\section{Gambar 1 Kerangka Berfikir}

Ha1: X1 memiliki dampak positif dan signifikan terhadap Y.

Hb2: X2 memiliki dampak positif dan signifikan terhadap Y.

Hc3: Y Pada saat yang sama, X1 dan X2 memiliki dampak positif dan signifikan terhadap $\mathrm{Y}$.

\section{METODOLOGI PENELITIAN}

\section{A. Jenis Penelitian}

Penelitian ini dilaksanakan di PT Tirta Varia Intipratama.Jl. Daan Mogot no.46, Kedaung Kali angke, Cengkareng Jakarta barat.

Definisi Sugiyono (2011: 44), jenis penelitian asosiatif.yaitu "penelitian ini bermaksud untuk mengetahui efek atau hubungan dua variabel lainnya".

\section{B. Hasil Penelitian}

\section{Uji Instrumen}

a. Uji Validitas

Definisi Sugiyono (2011:267) "validitas merupakan tingkat keakuratan data yang dihasilkan oleh subjek dan data dilaporkan oleh para peneliti ". Pengujian validitas digunakan dengan menggunakan analisis faktor tujuannya untuk memastikan setiap pertanyaan diklarifikasikan tentang variabel yang telah dibuat

\section{b. Uji Reliabilitas}

Definisi Ghozali (2013:78) Reliabilitas ialah tingkat kepercayaan dalam kuesioner. ketika mencoba mereproduksi data dalam kelompok yang sama, responden tidak menganggap adanya perubahan psikologis. Kuesioner dianggap dapat diandalkan jika hasil uji statistik Alpha> 0,0, 60 


$$
r_{11}=\left[\frac{k}{k-1}\right]\left[1 \frac{\sum \sigma^{2}}{\sigma_{1}^{2}}\right]
$$

Keterangan:

$$
\begin{array}{ll}
r_{11} & =\text { Koefisien reliabilitas } \\
\mathrm{k} & =\text { Jumlah butir pertanyaan } \\
\sum \sigma^{2} & =\text { Jumlah Variansi butir pertanyaan } \\
\sigma_{1}{ }^{2} & =\text { Varians total }
\end{array}
$$

\section{Uji Asumsi Klasik}

Yaitu memastikan persamaan garis regresi dihasilkan (valid) untuk menemukan prediksi, beberapa tes akan dilakukan:

\section{a. Uji Normalitas}

Maksud uji normalitas iyalah menentukan apakah variabel dependen dan variabel independen dalam model regresi memiliki distribusi normal,

\section{b. Uji Multikolinieritas}

Defimisi Ghozali (2013: 82), linearitas multicolor adalah hubungan linear sempurna antara beberapa atau semua variabel independen.

1) Koefisien inflasi / variabel SWF mendefinisikan model regresi multi-warna, yaitu SWF kurang dari 10.

2) Ukuran Pedoman Toleransi untuk model regresi non-warna dengan nilai toleransi $>0,1$

\section{c.Uji Heteroskedastisitas}

Definisi Ghozali (2013: 83), tujuan untuk menguji apakah model regresi memiliki varian tidak merata antara residu dari satu ke yang lain".Dengan melihat grafik perkiraan antara tingkat variabel (zpred) dan residu (lembek) tanpa adanya skema eksplisit.

\section{Koefisien Korelasi}

Definisi Sugiyono (2011: 185), uji korelasi untuk mengetahui hubungan dependen $(\mathrm{X})$ dan 1 independen $(\mathrm{Y})$ menggunakan pendekatan koefisien korelasi Pearson dengan rumus:

$$
\mathbf{r x y}=\frac{\mathbf{n} \sum \mathbf{X Y}-\left(\sum \mathbf{Y}\right)\left(\sum \mathbf{Y}\right)}{\sqrt{\left\{\mathbf{n} \sum \mathbf{X}^{2}-\left(\sum \mathbf{X}\right)^{2}\right\}\left\{\mathbf{n} \sum \mathbf{Y}^{2}-\left(\sum \mathbf{Y}\right)^{2}\right\}}}
$$

$$
\begin{aligned}
& \text { Keterangan: } \\
& \text { Ixy = koefisien korelasi antar X dan Y } \\
& \mathrm{n} \quad=\text { Jumlah responden } \\
& \mathrm{X} \quad=\text { Skor item kuesioner } \\
& \mathrm{Y} \quad=\text { Total skor item kuesioner } \\
& \Sigma \mathrm{X}^{2}=\text { Jumlah kuadrat seluruh skor } \mathrm{X} \\
& \Sigma \mathrm{Y}^{2} \quad=\text { Jumlah kuadrat seluruh skor } \mathrm{Y}
\end{aligned}
$$


4. Analisis Regresi Linier Berganda

Untuk mengetahui sejauh mana variabel yaitu: (X1) dan (Y).

$\mathbf{Y}=\mathbf{a}+\mathbf{b} \square \mathrm{X} \square+\mathbf{b} \square \mathrm{X} \square+\mathbf{e}$

$$
\begin{aligned}
& \text { Keterangan: } \\
& \mathrm{Y} \quad=\text { Kinerja Karyawan } \\
& \mathrm{a} \quad=\text { Konstanta } \\
& \mathrm{b} \square, \mathrm{b} \mathrm{g}_{0}=\text { Koefisien Regresi } \\
& \mathrm{X}_{1} \quad=\text { Gaya Kepemimpinan Transformasional } \\
& \mathrm{X}_{2} \quad=\text { Motivasi } \\
& \mathrm{e} \quad=\text { Kesalahan pengukuran (eror) }
\end{aligned}
$$

\section{Uji Hipotesis}

\section{a. Uji Signifikan Parsial T}

Untuk mengetahui model regresi variabel $(\mathrm{X})$ memiliki pengaruh signifikan terhadap variabel (Y)

\section{b. Uji Signifikan Simultan F}

Apakah variabel independen secara bersama-sama mempengaruhi variabel dependen dengan kepercayaan $95 \%$ dan $\alpha=5 \%$. Kriteria tes itu:

\section{c. Koefisien Determinasi $\left(\mathbf{R}^{\mathbf{2}}\right)$}

Defimisi Ghozali (2013: 46) Koefisien determinasi dan dari nol menjadi satu. Nilai R2 yang rendah berarti kemampuan variabel independen untuk menjelaskan variasi dalam variabel dependen sangat terbatas. Gunakan rumus :

\section{Hasil Penelitian}

$$
\mathrm{KD}=\mathrm{R}^{2} \times 100 \%
$$

\section{A. Pengujian Instrumen}

1) Uji Validitas

Tabel 4.5

Uji Validitas Gaya Kepemimpinan Transformasional $\left(\mathrm{X}_{1}\right)$

\begin{tabular}{|c|l|c|c|c|}
\hline Variabel & Pernyataan & $\begin{array}{c}\text { Nilai r } \\
\text { hitung }\end{array}$ & $\begin{array}{c}\text { Nilai r } \\
\text { tabel }\end{array}$ & Keterangan \\
\hline \multirow{4}{*}{$\begin{array}{c}\text { Gaya } \\
\text { Kepemimpinan } \\
\text { Transformasional } \\
\left(\mathrm{X}_{1}\right)\end{array}$} & Pemyataan 1 & 0.430 & 0,179 & Valid \\
\cline { 2 - 5 } & Pemyataan 2 & 0.396 & 0,179 & Valid \\
\cline { 2 - 5 } & Pemyataan 3 & 0.821 & 0,179 & Valid \\
\cline { 2 - 5 } & Pemyataan 4 & 0.605 & 0,179 & Valid \\
\cline { 2 - 5 } & Pemyataan 5 & 0.439 & 0,179 & Valid \\
\cline { 2 - 5 } & Pemyataan 6 & 0.277 & 0,179 & Valid \\
\cline { 2 - 5 } & Pemyataan 7 & 0.522 & 0,179 & Valid \\
\cline { 2 - 5 } & Pemyataan 8 & 0.597 & 0,179 & Valid \\
\cline { 2 - 5 } & Pemyataan 9 & 0.779 & 0,179 & Valid \\
\cline { 2 - 5 } & Pemyataan 10 & 0.789 & 0,179 & Valid \\
\hline
\end{tabular}

Tabel 4.5 menunjukkan nilai $r$ total lebih besar dari nilai $r$ tabel $(0,179)$, dapat didefimisikansemua butir pernyataan dalam variabel gaya kontrol transformasikvalid. 
Tabel 4.6

Uji Validitas Motivasi Kerja $\left(\mathbf{X}_{2}\right)$

\begin{tabular}{|c|l|c|c|c|}
\hline Variabel & Pernyataan & $\begin{array}{c}\text { Nilai r } \\
\text { hitung }\end{array}$ & $\begin{array}{c}\text { Nilai } \mathbf{r} \\
\text { tabel }\end{array}$ & Keterangan \\
\hline \multirow{5}{*}{$\begin{array}{c}\text { Motivasi Kerja } \\
\text { (X2) }\end{array}$} & Pemyataan 1 & 0.409 & 0,179 & Valid \\
\cline { 2 - 5 } & Pemyataan 2 & 0.460 & 0,179 & Valid \\
\cline { 2 - 5 } & Pemyataan 3 & 0.517 & 0,179 & Valid \\
\cline { 2 - 5 } & Pemyataan 4 & 0.535 & 0,179 & Valid \\
\cline { 2 - 5 } & Pemyataan 5 & 0.513 & 0,179 & Valid \\
\cline { 2 - 5 } & Pemyataan 6 & 0.555 & 0,179 & Valid \\
\cline { 2 - 5 } & Pemyataan 7 & 0.594 & 0,179 & Valid \\
\cline { 2 - 5 } & Pemyataan 8 & 0.618 & 0,179 & Valid \\
\cline { 2 - 5 } & Pemyataan 9 & 0.420 & 0,179 & Valid \\
\cline { 2 - 5 } & Pemyataan 10 & 0.630 & 0,179 & Valid \\
\hline
\end{tabular}

Sumber: Data Primer diolah dengan SPSS 22

Tabel 4.6 menunjukkan nilai $\mathrm{r}$ hitung lebih besar dari nilai $\mathrm{r}$ tabel $(0,179)$ dapat didefimisikansemua butir pernyataan variabel motivasi kerja adalah valid

Tabel 4.7

Uji Validitas Kinerja Karyawan (Y)

\begin{tabular}{|c|l|c|c|c|}
\hline Variabel & Pernyataan & $\begin{array}{c}\text { Nilai r } \\
\text { hitung }\end{array}$ & $\begin{array}{c}\text { Nilai r } \\
\text { tabel }\end{array}$ & Keterangan \\
\hline \multirow{5}{*}{$\begin{array}{c}\text { Kinerja } \\
\text { Karyawan (Y) }\end{array}$} & Pernyataan 1 & 0.402 & 0,179 & Valid \\
\cline { 2 - 5 } & Pernyataan 2 & 0.477 & 0,179 & Valid \\
\cline { 2 - 5 } & Pernyataan 3 & 0.604 & 0,179 & Valid \\
\cline { 2 - 5 } & Pernyataan 4 & 0.575 & 0,179 & Valid \\
\cline { 2 - 5 } & Pernyataan 5 & 0.583 & 0,179 & Valid \\
\cline { 2 - 5 } & Pernyataan 6 & 0.470 & 0,179 & Valid \\
\cline { 2 - 5 } & Pernyataan 7 & 0.650 & 0,179 & Valid \\
\cline { 2 - 5 } & Pernyataan 8 & 0.540 & 0,179 & Valid \\
\cline { 2 - 5 } & Pernyataan 9 & 0.485 & 0,179 & Valid \\
\cline { 2 - 5 } & Pernyataan 10 & 0.375 & 0,179 & Valid \\
\hline
\end{tabular}

Sumber : Data Primer diolah dengan SPSS 22

Tabel 4.7 menunjukkan total nilai $r$ lebih besar dari $r$ tabel $(0,179)$, sehingga semua butir pernyataan dalam variabel aktivitas karyawan validUji Reliabilitas

Tabel 4.8

Hasil Uji Reliabilitas

\begin{tabular}{|l|c|c|c|}
\hline \multicolumn{1}{|c|}{ Variabel } & $\begin{array}{c}\text { Cronbach } \\
\text { Alpha }\end{array}$ & Kriteria & Keputusan \\
\hline $\begin{array}{l}\text { Kepemimpinan } \\
\text { Transformasional }\left(\mathrm{X}_{1}\right)\end{array}$ & 0,771 & $>0,60$ & Reliabel \\
\hline Motivasi Kerja $\left(\mathrm{X}_{2}\right)$ & 0,710 & $>0,60$ & Reliabel \\
\hline Kinerja Karyawan $(\mathrm{Y})$ & 0,696 & $>0,60$ & Reliabel \\
\hline
\end{tabular}

Sumber: Hasil Olahan Data SPSS 22

Tabel 4.8 setiap variabel antara variabel $\mathrm{X} 1, \mathrm{X}$, dan Y ternyata nilai Kronbach Alpha sebesar 60 0,60. Dengan demikian, hasil uji reliabilitas untuk semua variabel dapat diandalkan.

\section{B. Asumsi Klasik}

\section{1) Uji Normalitas Data}




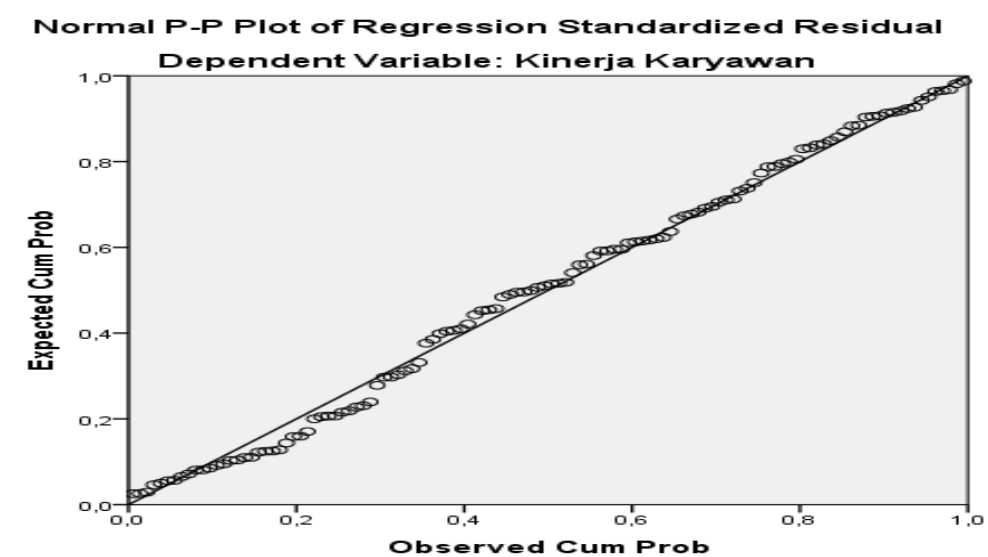

Gambar 4.2

\section{Uji Normalitas Data P-P Plot}

Melihat diagram probabilitas normal di atas, dapat disimpulkan bahwa diagram probabilitas normal, sehingga dapat disimpulkan dapat diketahui penelitian ini berdistribusi normal.

\section{2). Uji Multikolineritas}

Tabel 4.9

Uji Multikolinearitas

\begin{tabular}{|c|c|c|}
\hline \multirow{2}{*}{ Model } & \multicolumn{2}{|c|}{ Collinearity Statistics } \\
\hline & Tolerance & VIF \\
\hline 1 (Constant) & & \\
\hline Kepemimpinan Transformasional & 961 & 1,040 \\
\hline Motivasi Kerja & 961 & 1,040 \\
\hline
\end{tabular}

Tabel 4.9 tersebut dapat disimpulkan nilai toleransi dan SWF untuk masing-masing variabel:

(a) Nilai toleransi untuk variabel kontrol transformasi (X1) adalah 0,961> 0,10 , berarti variabel tidak terjadi dengan gejala multicolor.

(b) Nilai toleransi variabel (X2) adalah $0,961>0,10$, yang berarti tidak terjadi korelasi

\section{.3) Uji Heteroskedastisitas}

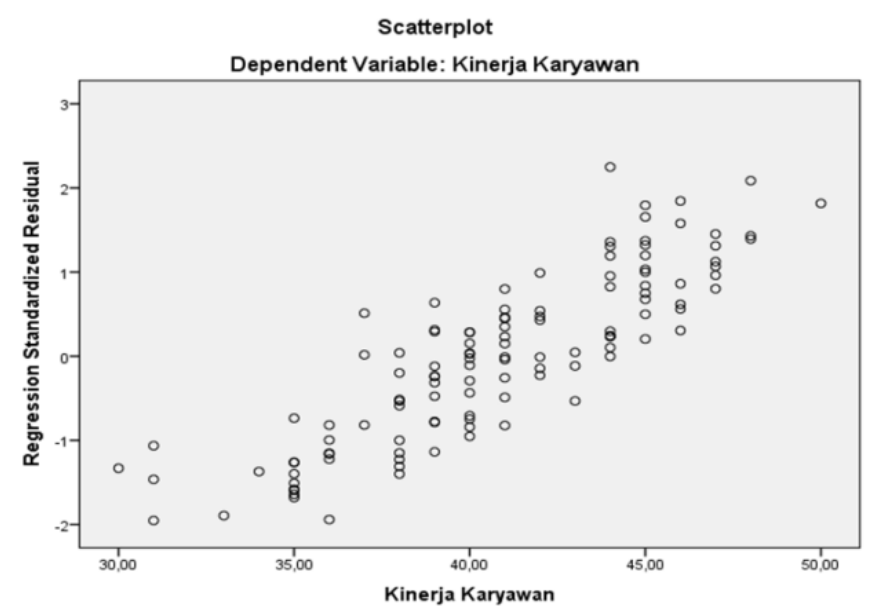

Gambar 4.3

Pengujian Heteroskedastisitas. 
Dari grafik ini Anda dapat melihat titik-titik merambat tidak teratur, tidak membentuk pola yang jelas, dan merambat di atas dan di bawah angka 0 di sepanjang sumbu Y, sehingga tidak ada heterosadensitas.

\section{Pengujian Hipotesis}

a.Uji Hipotesis Parsial

1). Uji Hipotesis I

Tabel 4.19

Ujit hitung Kepemimpinan Transformasional

\begin{tabular}{|c|c|c|c|c|}
\hline Model & thitung & $t$ tabel & Sig. & Keterangan \\
\hline $\begin{array}{l}\text { Kepemimpinan } \\
\text { Transformasional }\end{array}$ & 4,019 & 1,984 &, 000 & Signifikan \\
\hline
\end{tabular}

a. Dependent Variable: Kinerja Karyawan

Sumber: Hasil Olahan Data SPSS 72 .

T hitung transformasional kepemimpinan (X1) adalah 4,019> t tabel 1,984 (lampiran) menunjukkan bahwa kepemimpinan transformasional (X1) memiliki pengaruh positif dan signifikan terhadap kinerja karyawan (Y) pada kepemimpinan transformasional.

\section{2) Uji Hipotesis II}

\section{Tabel 4.20}

Uji t hitung Motivasi Kerja Terhadap Kinerja Karyawan

\begin{tabular}{|c|r|r|r|l|}
\hline Model & thitung & $t$ tabel & Sig. & Keterangan \\
\hline Motivasi Kerja & 4,101 & 1,984 &, 000 & Signifikan \\
\hline
\end{tabular}

a. Dependent Variable: Kinerja Karyawan

Sumber: Hasil Olahan Data SPSS 22

Nilai motivasi kerja hitung (X2) sebesar 4,101> t tabel 1,984 (terlampir) menunjukkan (X2) memiliki pengaruh positif. dan (Y) pada PT. Tirta Varia Intipratama

\section{b). Uji Hipotesis Simultan atau uji F}

Tabel 4.21

ANOVA $^{a}$

\begin{tabular}{|l|r|r|r|r|l|}
\hline Model & \multicolumn{1}{|c|}{$\begin{array}{c}\text { Sum of } \\
\text { Squares }\end{array}$} & \multicolumn{1}{c|}{ df } & Mean Square & F & Sig. \\
\hline 1 Regression & 548,409 & 2 & 274,204 & 20,529 &, $000^{\mathrm{b}}$ \\
Residual & 1562,791 & 117 & 13,357 & & \\
$\quad$ Total & 2111,200 & 119 & & & \\
\hline
\end{tabular}

a. Dependent Variable: Kinerja Karyawan

b. Predictors: (Constant), Motivasi Kerja, Kepemimpinan

Transformasional

Sumber: Hasil Olahan Data SPSS 22

Tabella di Berdasarkan 4,21 hasil estimasi F hitung sebesar 20,529 tingkat signifikansi sebesar $0,000<0,05$. Sedangkan nilai $\mathrm{F}$ tabel sebesar 3,07 (dari perhitungan $\mathrm{df}=2=0,05 \mathrm{dan} \mathrm{dk}=120-2-1=117$ diperoleh $\mathrm{F}$ tabel 3,07). Ini berarti nilai Fhitung 20,529> Ftabel 3,07 con originine originaria 
$0,000<0,05$ con artinya Kepemimpinan Transformasional $\left(\mathrm{X}_{1}\right)$ kerja motivasi $\left(\mathrm{X}_{2}\right)$ PT. Tirta Varia Intipratama

\section{KESIMPULAN DAN SARAN}

\section{A. Kesimpulan}

1. Memberikan pengaruh positif dan signifikan (X1) pada (X2) di PT. Tirta Varia Intipratama. Dapat ditunjukkan dengan nilai regresi yang diperoleh, yaitu $\mathrm{Y}=17.498+0.285 \mathrm{X}$, nilai koefisien korelasi 0.326 , koefisien determinasi $15.3 \%$ dan nilai hitung 4.019> t tabel 1.998 (terlampir) dengan signifikan 0,000<0,05.

2. Ada pengaruh positif dan signifikan motivasi kerja terhadap kinerja karyawan di PT. Tirta Varia Intipratama. Hal ini nilai regresi yang diperoleh $\mathrm{Y}=17,498+0,305 \mathrm{X}$ nilai koefisien korelasi 0,333 , koefisien determinasi $15,8 \%$ dan nilai thitung 4,101> ttabel 1,998 dengan signifikan $0,000<0,05$.

3. Secara bersama-sama terdapat pengaruh yang positif dan signifikan gaya kepemimpinan transformasional dan motivasi kerja terhadap kinerja karyawan pada PT. Tirta Varia Intipratama. Persamaan regresi linier berganda, $\mathrm{Y}=17.498+0.285 \mathrm{X} 1+0.305 \mathrm{X} 2$, koefisien korelasi adalah 0.510 , koefisien determinasi adalah $26 \%$ dan nilai $\mathrm{F}$ yang dihitung adalah 20.529> Ftable 3.07 dengan signifikan 0,000<0,05.

\section{B. Saran}

1. Pada indikator motivasi inspirasional, maka penulis menyarankan agar pimpinan PT. Tirta Varia Intipratama hendaknya lebih komitmen memberikan sanksi bagi karyawan yang melanggar aturan di dalam perusahaan, agar karyawan lebih disiplin dalam bekerja.

2. Pada indikator kebutuhan rasa aman maka penulis menyarankan agar. pimpinan PT. Tirta Varia Intipratama hendaknya agar lebih memperhatikan kebutuhan para karyawan yang berhubungan dengan rasa aman seperti kebutuhan psiologis pelatihan untuk menambahkan keahlian karyawan.

3. Pada indikator tanggung jawab maka penulis menyarankan agar karyawan. pimpinan PT. Tirta Varia Intipratama hendaknya menamakan kepada karyawan rasa tanggung jawab terhadap pekerjaan yang diberikan perusahaan, Memberikan reward sehingga karyawan merasa dihargai pekerjaannya sehingga karyawan akan bekerja ihlkas tidak hanya semata-mata rutinitas saja.

\section{DAFTAR PUSTAKA}

Avolio, B.J., Zhu, W., Koh, W., and Bhatia, P. 2004. Transformational Leadership and Organizational Commitment: Mediating Role of Psychological Empowerment and Moderating Role of Structural Distance. Journal of Organizational Behavior, Vol. 25, pp. 951-968

Bangun, Wilson. 2012. “Manajemen Sumber Daya Manusia”. Jakarta: Erlangga

Bass, B.M. 2011. Leadership and Performance Beyond Expectations. The Free Press. Jakarta: Ghalia Indonesia

Ghozali, Imam. 2013.Aplikasi Analisis Multivariate dengan Program IBM SPSS

20. Semarang: Badan Penerbit - Universitas Diponegoro. 
Priansa, Donni Juni. 2014. Perencanaan dan Pengembangan Sumber Daya Manusia. Bandung: Alfabeta

Rahyuda. 2013. Pengaruh Kompensasi, Pelatihan, Kepemimpinan, dan Lingkungan Kerja terhadap Kinerja Pegawai di PT Askes (Persero) Kantor Cabang Denpasar: Tesis Program Studi Magister Manajemen Program Pasca Sarjana Universitas Udayana Denpasar.

Ranupandojo, H., dan Suad Husnan, 2002, Manajemen Personalia, Yogyakarta: BPFE.

Robertus Yuniawan 2014. Manajemen. Jakarta: Erlangga.

Sugiyono. 2011. Metode Penelitian Kuantitatif, Kualitatif dan R\&D. Bandung: Alfabeta.

Sutrisno, Edy. 2013. Manajemen Sumber Daya Manusia, Cetakan Kelima. Yogyakarta: Prenada Media

Yuki.A,Gery Prilaku Organisasi Psikologi personalia. 2013. Jakarta: Cetakan Pertama. Alih Bahasa Muh Shobaruddin. Bina Aksara.Hal 224 